Check for updates

Cite this: RSC Adv., 2019, 9, 39824

Received 27th October 2019

Accepted 7th November 2019

DOI: $10.1039 / c 9 r a 08825 c$

rsc.li/rsc-advances

\section{Synthesis of a novel hexaazatriphenylene derivative for the selective detection of copper ions in aqueous solution $\uparrow$}

\begin{abstract}
Tahseen S. Saeed, (ID $\mathbf{t}^{* a}$ Dinesh Maddipatla, (D) $\ddagger^{* \mathrm{~b}}$ Binu B. Narakathu, ${ }^{\mathrm{b}}$ Sarah S. Albalawi, ${ }^{a}$ Sherine O. Obare ${ }^{c}$ and Massood Z. Atashbar ${ }^{b}$

A hexaazatriphenylene (HAT) derivative, naphtho[2,3-h]naphtho[2', 3':7,8]quinoxalino[2,3-a]naphtho $\left[2^{\prime}, 3^{\prime}: 7,8\right]$ quinoxalino[2,3-c]phenazine-5,10,15,20,25,30-hexaone (NQH) was synthesized, characterized, and found to have novel properties in being selective toward the detection of copper $\left(\mathrm{Cu}^{2+}\right)$ ions. The capability of $\mathrm{NQH}$ to be employed as a colorimetric, chemo-fluorescence and electrochemical sensor for the detection of $\mathrm{Cu}^{2+}$ was demonstrated by performing UV-Vis absorbance, fluorescence intensity, and cyclic voltammetry (CV) measurements. The interaction between $\mathrm{NQH}$ and $\mathrm{Cu}^{2+}$ was initially observed with an obvious color change from yellow to brown upon the addition of $\mathrm{Cu}^{2+}$ ions to $\mathrm{NQH}$. The interaction was also confirmed by UV-Vis absorbance, fluorescence intensity, and mass spectroscopy (MS/MS) measurements. UV absorbance, fluorescence and $\mathrm{CV}$ of $\mathrm{NQH}$ toward $\mathrm{Cu}^{2+}$ showed good linearity with a detection limit of $3.32 \mu \mathrm{M}, 2.20 \mu \mathrm{M}$ and $0.78 \mu \mathrm{M}$, respectively, which are lower than the toxicity levels of copper in drinking water $(20-30 \mu \mathrm{M})$ set by the U.S. Environmental Protection Agency (EPA) and World Health Organization (WHO). A 1:2 stoichiometry complexation between $\mathrm{NQH}$ and $\mathrm{Cu}^{2+}$ was confirmed by Job's plot and MS/MS. In addition, the selectivity and sensitivity of the $\mathrm{NQH}$ compound towards $\mathrm{Cu}^{2+}$ ions were further confirmed by performing $\mathrm{CV}$ on a screen printed flexible and planar electrochemical sensor.
\end{abstract}

\section{Introduction}

Heavy metals such as lead (Pb), cadmium (Cd), mercury $(\mathrm{Hg})$, Arsenic (As) and copper $(\mathrm{Cu})$ present in the environment impact biological species (humans, plants and animals) living in it. ${ }^{1-3}$ Exposure to the heavy metals causes adverse health effects on the living organisms. ${ }^{4,5}$ Among the various heavy metals, copper is a non-biodegradable metal and its ion $\left(\mathrm{Cu}^{2+}\right)$ an essential micronutrient that supports the fundamental physiological processes of living organisms. ${ }^{6-8}$ However, the excessive consumption of $\mathrm{Cu}^{2+}$ may result in its accumulation in soft tissues causing many health and physiological diseases including ischemic heart disease, anemia, kidney and liver damage, gastrointestinal disturbance, severe intravascular hemolysis, hepatotoxicity and acute renal failure. ${ }^{9-11}$ In

\footnotetext{
${ }^{a}$ Department of Chemistry, Western Michigan University, Kalamazoo, Michigan-49008, USA. E-mail: tahseensulaima.saeed@wmich.edu

${ }^{b}$ Department of Electrical and Computer Engineering, Western Michigan University, Kalamazoo, Michigan-49008, USA.E-mail: dinesh.maddipatla@wmich.edu

'Department of Nanoscience, Joint School of Nanoscience and Nanoengineering, University of North Carolina at Greensboro, Greensboro, NC 27401, USA

$\dagger$ Electronic supplementary information (ESI) available. See DOI: 10.1039/c9ra08825c

\$ Dinesh Maddipatla and Tahseen S. Saeed contributed equally to this work, thus both should be considered as the first authors.
}

addition, high exposure to $\mathrm{Cu}^{2+}$ can cause slow memory loss in elderly people with Wilson's disease. ${ }^{\mathbf{1 1}, 12}$ Therefore, the accurate detection of $\mathrm{Cu}^{2+}$ ions in environmental and biological samples is very important.

Many techniques have been developed for the detection of $\mathrm{Cu}^{2+}$ ions including inductively coupled plasma atomic emission spectrometry (ICP-AES), atomic absorption spectrometry (AAS), inductively coupled plasma mass spectrometry (ICP-MS), chromatography, gravimetric detection and photometry. ${ }^{\mathbf{1 3 - 1 9}}$ However, most of these techniques are complex, bulky, timeconsuming, non-portable and require relatively expensive apparatus as well as trained professionals to operate. To overcome these limitations, optical and electrochemical techniques such as UV-Vis, fluorescence, electrochemical impedance spectroscopy (EIS) and cyclic voltammetry (CV) can be used for the detection of $\mathrm{Cu}^{2+}$ ions cost effectively. ${ }^{20,21}$ However, chemical compounds that exhibit both optical and electrochemical properties which are selective and sensitive only towards $\mathrm{Cu}^{2+}$ ions have not been explored well enough. So, there is a need to synthesize novel materials that possess both optical and electrochemical properties towards only $\mathrm{Cu}^{2+}$ ions, over other heavy metal ions.

Over the last decade, polycyclic aromatic hydrocarbons $(\mathrm{PAH})$ have been receiving more attention in nanoscience and materials related fields for various applications due to their 
high charge-carrier mobility and tailorability. ${ }^{22,23}$ However, it has been reported that some of the linear PAHs are not stable because of its narrow band gaps and low ionization potentials. ${ }^{24}$ To stabilize PAHs, the $\mathrm{CH}$ atoms must be replaced by heteroatoms such as nitrogen $(\mathrm{N})$ /sulfur/selenium, and twodimensional (2D) acene analogues must be created by annealing the aromatic rings of PAHs onto adjacent rings. ${ }^{25}$ This will effectively increase the intermolecular surface overlap. $^{26}$

Among heteroatom-substituted PAHs, hexaazatriphenylene (HAT) is one of the smallest $2 \mathrm{D} \mathrm{N}$-containing polyheterocyclic aromatic systems and is an electron deficient, planar and rigid conjugated structure with superior pi-pi stacking ability. ${ }^{24}$ HAT and its derivatives can be tuned by modifying the readily available six substituent groups resulting in different coordination structures. ${ }^{27}$ This enables numerous applications for HAT and its derivatives in the development of n-type semiconductors, ligands for coordination chemistry, sensors, liquid crystals, magnetic materials and micro-porous for storing energy. ${ }^{24,28-30}$ HAT based derivatives have also been used in optical applications due to their unique capability in recognizing metal ions and faster reaction toward heavy metals. ${ }^{30,31}$ These derivatives synthesized with different coordination structures using phenyl or methyl groups have been investigated for selective detection of heavy metals such as Zinc (Zn) and $\mathrm{Cd}$ over other heavy metal ions. ${ }^{32,33}$ However, there is no information available on the selective chemical detection capabilities of HAT derivatives towards $\mathrm{Cu}^{2+}$ ions with various modified structures such as quinone groups. Thus, an investigation to explore the capability of HAT derivatives to detect $\mathrm{Cu}^{2+}$ ions is highly desired.

In this work, a novel HAT derivative compound, naphtho[2,3h]naphtho[2', $\left.2^{\prime}: 7,8\right]$ quinoxalino[2,3- $\left.a\right]$ naphtho[ $\left[2^{\prime}, 3^{\prime}: 7,8\right]$ quinoxalino[2,3-c]phenazine-5,10,15,20,25,30-hexaone (NQH) was synthesized for detecting $\mathrm{Cu}^{2+}$ ions using both optical and electrochemical detection techniques. NQH displays a high degree of metal-organic coordination interaction towards $\mathrm{Cu}^{2+}$ among many different ions in aqueous mixture. The optical detection capability of the NQH compound towards $\mathrm{Cu}^{2+}$ ions was investigated by using UV-Vis and fluorescence techniques. In addition, the electrochemical detection capability of the $\mathrm{NQH}$ compound towards $\mathrm{Cu}^{2+}$ ions was also investigated by using CV technique. For electrochemical measurements, a three-electrode electrochemical sensor fabricated using additive screen printing process was employed. Printed electronics (PE) enable the fabrication of sensing devices at relatively lower cost with attractive features such as flexibility and high throughput with minimal material wastage. ${ }^{34-38}$ The optical and electrochemical measurements demonstrating the selectivity and sensitivity of $\mathrm{NQH}$ compound towards $\mathrm{Cu}^{2+}$ ions among various heavy metal ions is reported.

\section{Experimental}

\subsection{Chemicals and materials}

All chemicals were purchased from commercial sources and were used as received. Hexaketocyclohexane octahydrate, 1,2- phenylenediamine, glacial acetic acid, ethanol, and ethyl acetate, dichloro methane from Sigma Aldrich Chemical Company were used in the synthesis of NQH. All the metal salts including copper acetate $\left(\mathrm{Cu}\left(\mathrm{CH}_{3} \mathrm{COO}\right)_{2}\right)$, lithium chloride (LiCl), cobalt chloride $\left(\mathrm{CoCl}_{2}\right)$, ferrous chloride $\left(\mathrm{FeCl}_{2}\right)$, nickel chloride $\left(\mathrm{NiCl}_{2}\right)$, mercury chloride $\left(\mathrm{HgCl}_{2}\right)$, ferric chloride $\left(\mathrm{FeCl}_{3}\right)$ and lead acetate $\left(\mathrm{Pb}\left(\mathrm{C}_{2} \mathrm{H}_{3} \mathrm{O}_{2}\right)_{2}\right)$ were obtained from Sigma Aldrich Chemical Company and dissolved in deionized (DI) water for preparing the stock solutions, for concentrations ranging from $100 \mu \mathrm{M}$ to $1 \mu \mathrm{M}$. The stock solutions of metals prepared using DI water, with have $\mathrm{pH} 7$, were used directly for experiments/measurements without adding any buffers (used to alter the $\mathrm{pH}$ ) to avoid cross-contaminations. Dimethyl sulfoxide (DMSO) and dimethyl sulfoxide- $\mathrm{d}_{6}\left(\right.$ DMSO- $\left._{6}\right)$ from Sigma Aldrich Chemical Company were used in the preparation of $\mathrm{NQH}$ and ${ }^{1} \mathrm{HNMR}$ as well as ${ }^{13} \mathrm{C}$ NMR experiments, respectively. A $127 \mu \mathrm{m}$ thick transparent polyethylene terephthalate (Melinex® ST 506) from DuPont ${ }^{\mathrm{TM}}$ Teijin Films was employed as the substrate, for fabricating a flexible three electrode configuration electrochemical sensor. A flexible conductive silver ink (Ag 800) from Applied Ink Solutions was used for metalizing the counter electrode. A carbon conductive ink (DuPont 7105) and an $\mathrm{Ag} / \mathrm{AgCl}$ paste (DuPont 5874) from DuPont ${ }^{\mathrm{TM}}$ was used as the working and reference electrode, respectively. Isopropyl alcohol and ethylene glycol di-acetate from Sigma Aldrich Chemical Company was used for cleaning the substrate and screenprinting press, respectively.

\subsection{Apparatus}

A JEOL model JNMECP400 instrument was used to collect the ${ }^{1} \mathrm{H}$ NMR and ${ }^{13} \mathrm{C}$ NMR spectra of the NQH at $400 \mathrm{MHz}$ in DMSO$\mathrm{d}_{6}$. The NQH samples were introduced in the JEOL instrument at 5-10 $\mathrm{mL} \mathrm{min}^{-1}$ when the source temperature was maintained at $80{ }^{\circ} \mathrm{C}$ with nebulizing gas supply at $250 \mathrm{~L} \mathrm{~h}^{-1}$. UV-Vis absorbance spectra of the chemical compounds were recorded using a Varian Cary 50 Bio Spectrophotometer. A Varian Cary Eclipse fluorescence spectrometer was used to collect the fluorescence spectra. Mass spectrometry was performed using a Waters SYNAPT G1 HDMS ${ }^{\mathrm{TM}}$ instrument with electrospray ionization (ESI). The electrospray capillary voltage was set to 2 $\mathrm{kV}$ with a desolvation temperature of $150{ }^{\circ} \mathrm{C}$ while the sampling and extraction cones were set at $40 \mathrm{~V}$ and $1 \mathrm{~V}$, respectively. Interface $1010 \mathrm{E}$ from Gamry instruments was used as a potentiostat to measure and record CV as well as EIS responses of the NQH drop-casted electrochemical sensor. A spring-loaded small outline integrated circuit (SOIC) test clip from Pomona Electronics 6108 was used to connect the electrochemical sensor to the potentiostat. All the probes and wires were calibrated prior to obtaining the measurements.

\subsection{Synthesis of NQH}

Fig. 1 shows the synthesis of the $\mathrm{NQH}\left(\mathrm{C}_{48} \mathrm{H}_{18} \mathrm{~N}_{6} \mathrm{O}_{6}\right)$ compound. To synthesize NQH, initially 1,2-phenylenediamine (10.4 g, 96.0 $\mathrm{mmol})$ and hexaketocyclohexane octahydrate (10.0 g, 32.0 mmol) were refluxed particularly in $1: 1$ glacial acetic acid/ ethanol $(500 \mathrm{~mL})$ solvents at $140{ }^{\circ} \mathrm{C}$ for $3 \mathrm{~h}$ to reduce the total 


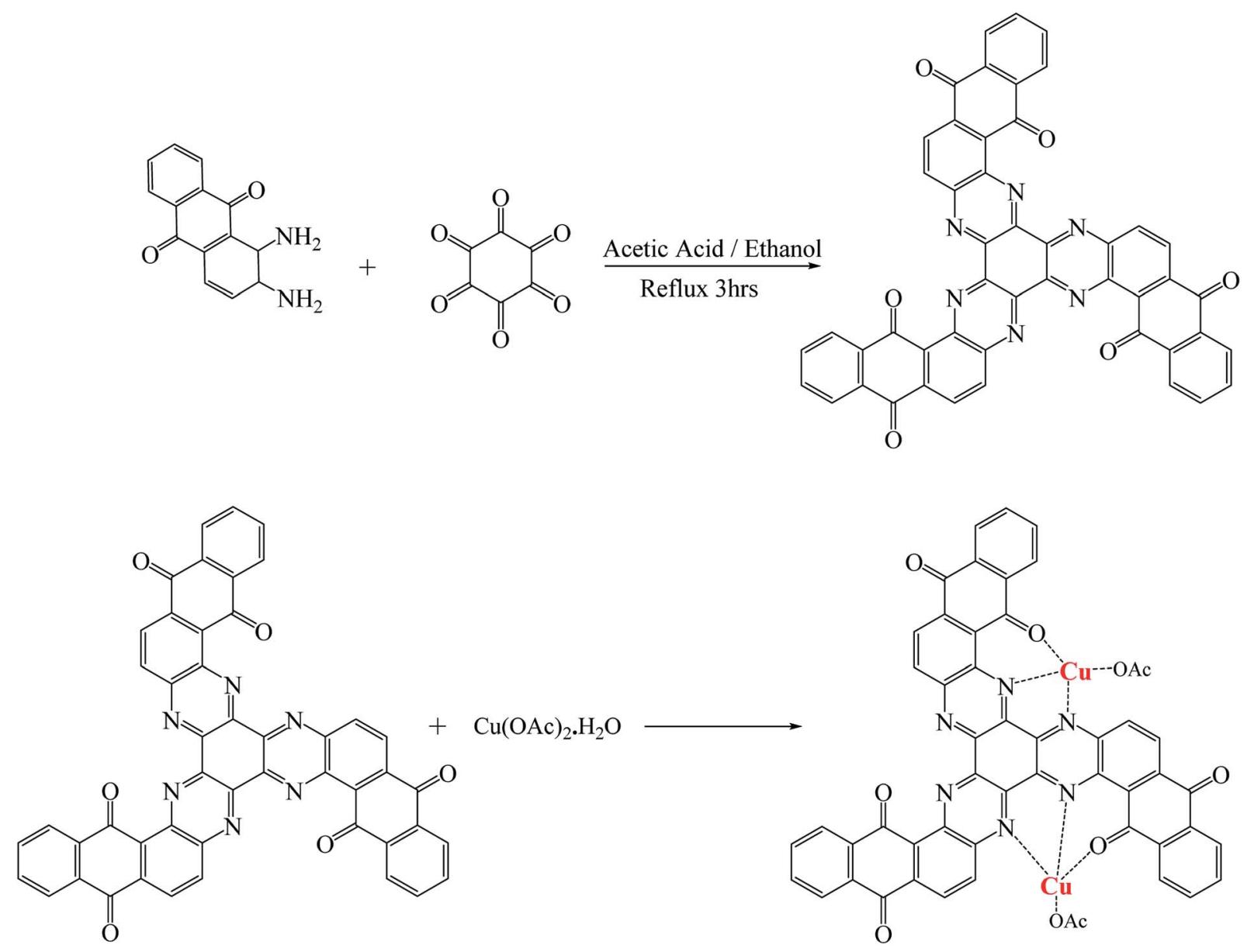

Fig. 1 Schematic representation of the synthesis of $\mathrm{NQH}$.

reaction time as well as to make the reaction more shifted toward Schiff base formation. After refluxing, the mixture was filtered using a $25 \mu \mathrm{m}$ pore size filter paper to remove the solvents and the remaining solid which is a HAT derivative. The mixture was washed with hot glacial acid $(200 \mathrm{~mL})$ to remove the impurities/residues and dried under vacuum for $1 \mathrm{~h}$. The precipitated powder obtained after drying in vacuum was then purified by column chromatography filled with silica gel using ethyl acetate, dichloro methane of $1: 1(\mathrm{v} / \mathrm{v})$ to produce a yellow colored liquid, NQH. Depending upon the requirement of the characterizations such as ${ }^{1} \mathrm{NMR}$, mass spectroscopy or UV-Vis, the obtained $\mathrm{NQH}$ liquid was converted to powder by further vacuum drying and dissolved in solvents such as DMSO- $\mathrm{d}_{6}$ or methanol or ethanol.

The prepared NQH was characterized by ${ }^{1} \mathrm{H}$ NMR as well as ${ }^{13} \mathrm{C}$ NMR spectroscopy to confirm its structure. The corresponding peaks for the NQH structure were identified at ${ }^{1} \mathrm{H}$ NMR (400 MHz, DMSO-d $\left.\mathrm{d}_{6}\right): \delta 8.16-8.30(2 \mathrm{H}, \mathrm{m}$, aromatic), 8.09$8.13(1 \mathrm{H}, \mathrm{d}, J 1 / 49.0 \mathrm{~Hz}$, aromatic), 7.86-7.95 $(4 \mathrm{H}, \mathrm{m}$, aromatic) ppm as shown in Fig. 2(a). The peaks observed for ${ }^{13} \mathrm{C}$ NMR (75 MHz, DMSO-d ${ }_{6}, \mathrm{~d}$ ppm): $\delta 126.8,127.1,132.1,133.6$, $135.5,135.7,137.1,137.9 \mathrm{ppm}$ corresponds to $-\mathrm{C}-\mathrm{N},-\mathrm{C}=\mathrm{O},-\mathrm{C}-$ C, $-\mathrm{C}-\mathrm{H}$ groups as shown in Fig. 2(b).

\subsection{Electrochemical sensor fabrication}

A schematic of the three-electrode electrochemical sensor with a working electrode (1700 $\mu \mathrm{m}$ radius), a counter electrode (inner and outer radius of $2900 \mu \mathrm{m}$ and $3900 \mu \mathrm{m}$ ) and a reference electrode $(1000 \mu \mathrm{m}$ width) is shown in Fig. 3(a). A screenprinting press (AMI MSP 485) from Affiliated Manufacturers Inc. was first calibrated and a stainless-steel screen frame fabricated at Microscreen ${ }^{\circledR}$, with electrode designs was installed. The wire diameter, mesh count and deflection angle of screen frame were $28 \mu \mathrm{m}, 325$ and $22.5^{\circ}$, respectively. The three inks carbon, $\mathrm{Ag} 800$ and $\mathrm{Ag} / \mathrm{AgCl}$ were screen printed, as the working, counter and reference electrodes, directly onto PET due to their better adhesion properties. The samples were then cured in a VWR oven at $100{ }^{\circ} \mathrm{C}$ for 10 minutes. The photograph of the screen-printed electrochemical sensor is shown in Fig. 3(b). A $160 \mu \mathrm{L} \mathrm{NQH} \mathrm{in} \mathrm{ethanol} \mathrm{solution} \mathrm{was} \mathrm{drop-casted} \mathrm{on}$ the working electrode of the printed sensor at $80^{\circ} \mathrm{C}$. Later, 120 $\mu \mathrm{L}$ of DI water was initially drop casted on the sensor to obtain a reference/blank signal. Then, $120 \mu \mathrm{L}$ of varying concentrations of $\mathrm{Cu}^{2+}$ and other heavy metals were drop casted on the $\mathrm{NQH}$ and their voltammetry responses were recorded at a scan rate of $50 \mathrm{mV} \mathrm{s}^{-1}$ and between potentials ranging from $-0.3 \mathrm{~V}$ to $1 \mathrm{~V}$. 


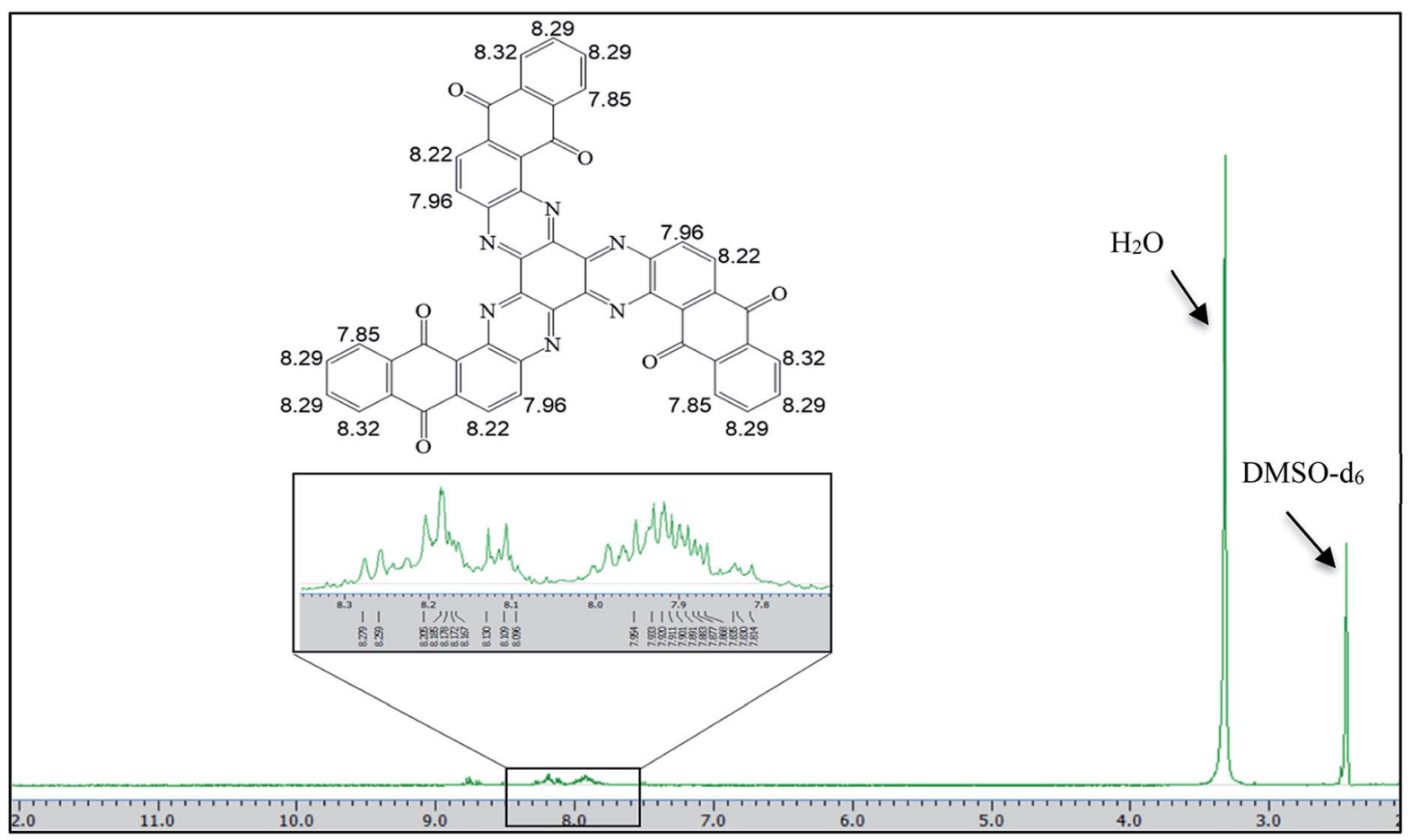

(a)

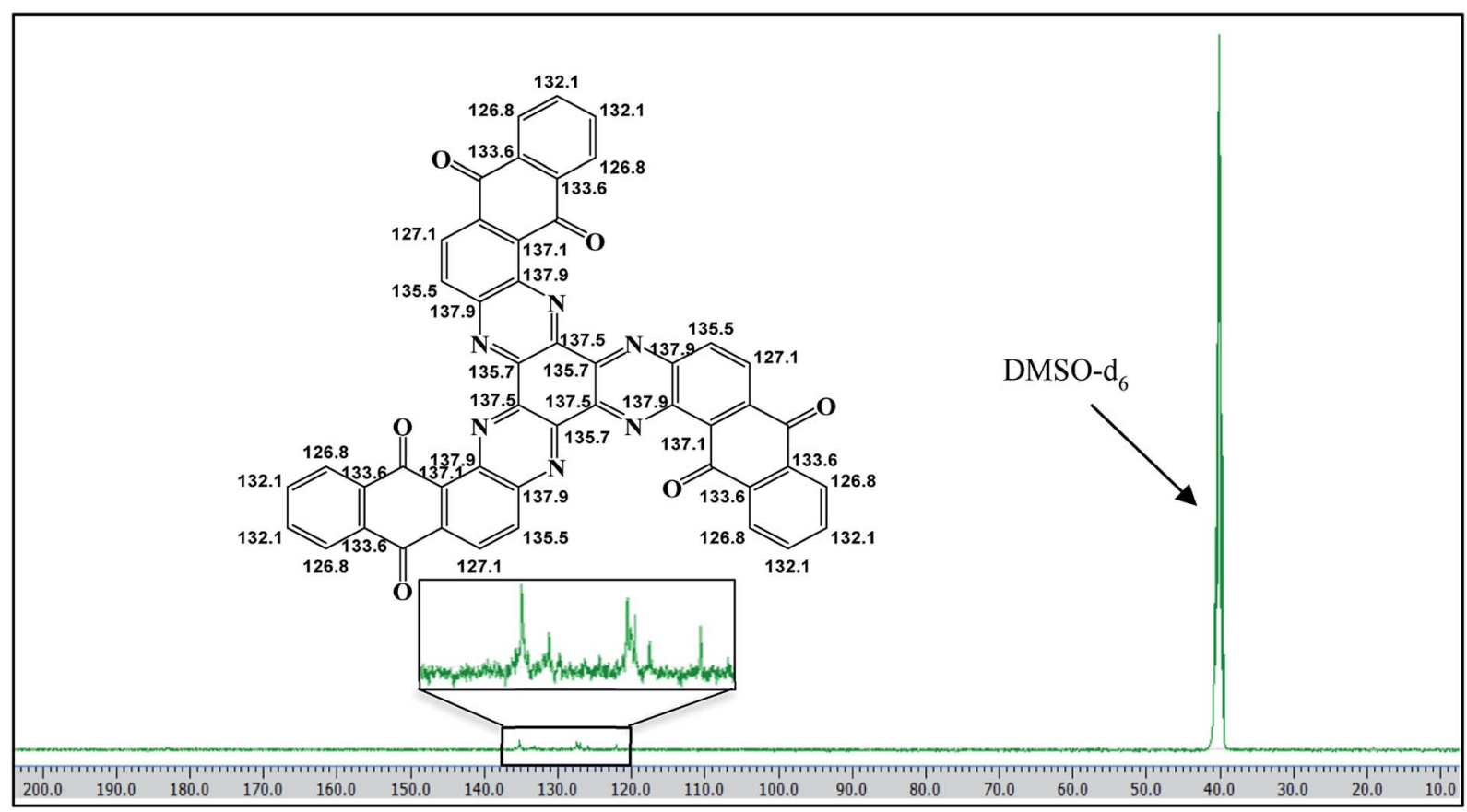

(b)

Fig. 2 (a) ${ }^{1} \mathrm{H}-\mathrm{NMR}$ and (b) ${ }^{13} \mathrm{C}-\mathrm{NMR}$ spectra of $\mathrm{NQH}$.

\section{Results and discussion}

\subsection{Monitoring changes in optical properties of $\mathrm{NQH}$ upon exposure to $\mathrm{Cu}^{2+}$}

The selectivity and the sensitivity of the NQH compound towards different heavy metals was investigated by using UV-Vis absorbance spectroscopy. Initially, UV-Vis absorption spectra of $\mathrm{NQH}$ was recorded in the presence of $100 \mu \mathrm{M}$ concentration of metal ions including $\mathrm{Cu}^{2+}, \mathrm{Co}^{2+}, \mathrm{Ni}^{2+}, \mathrm{Fe}^{2+}, \mathrm{Fe}^{3+}, \mathrm{Li}^{1+}, \mathrm{Pb}^{2+}$, and $\mathrm{Hg}^{2+}$ in aqueous media (Fig. 4(a)). An absorbance peak at $\sim 435 \mathrm{~nm}$ was observed for the $\mathrm{NQH}$ compound. No color change as well as no shift in peak was observed in the presence 


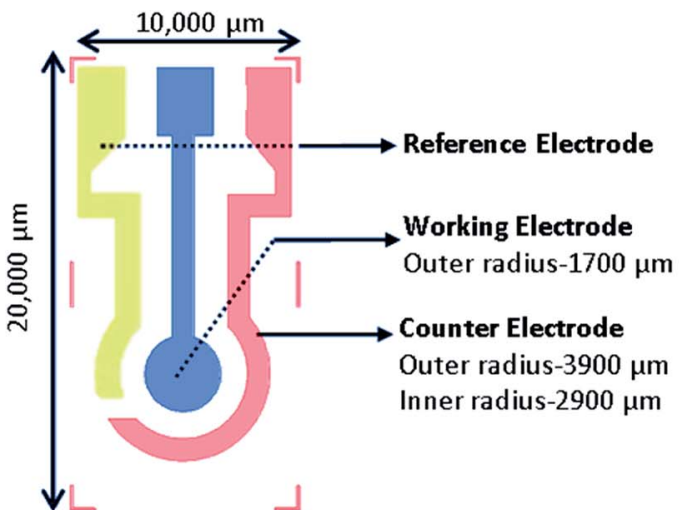

(a)
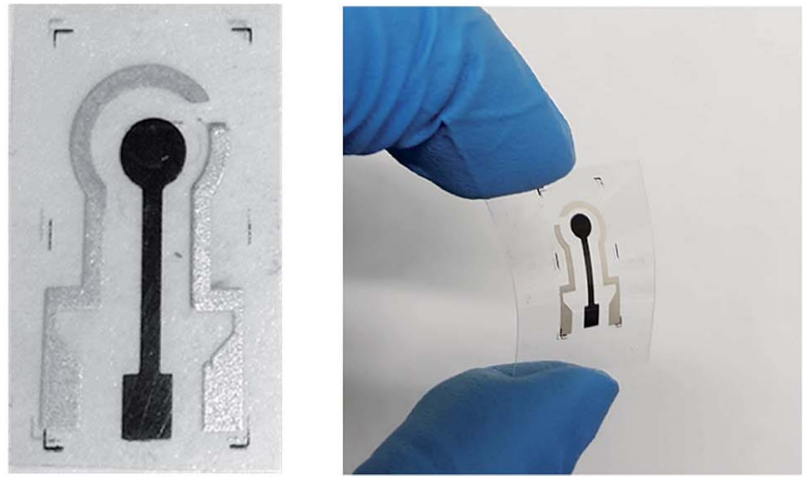

(b)

Fig. 3 (a) Schematic and (b) photograph of the screen printed electrochemical sensor.

of $\mathrm{NQH}$ with various metal ions except $\mathrm{Cu}^{2+}$. However, when the $\mathrm{Cu}^{2+}$ metal ions were added to the $\mathrm{NQH}$ compound, a change in color from yellow to brown as well as a shift in the absorbance peak from $\sim 435 \mathrm{~nm}$ to $\sim 485 \mathrm{~nm}$ was induced, implying a high

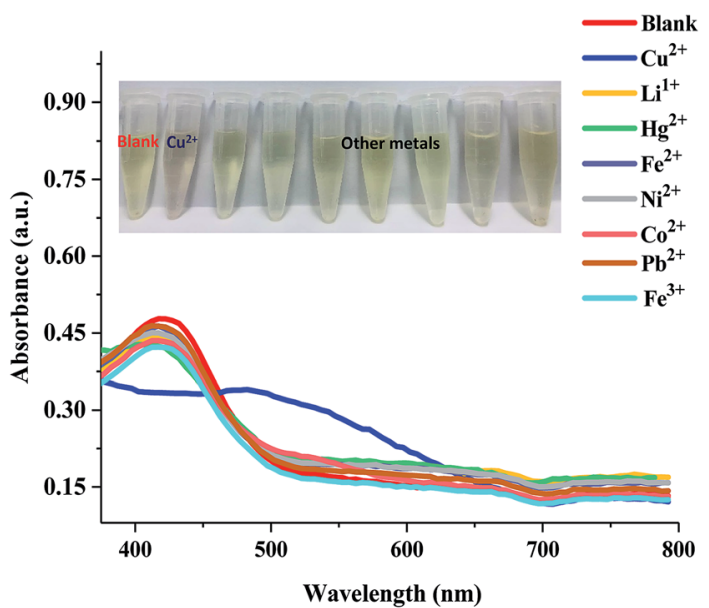

(a)

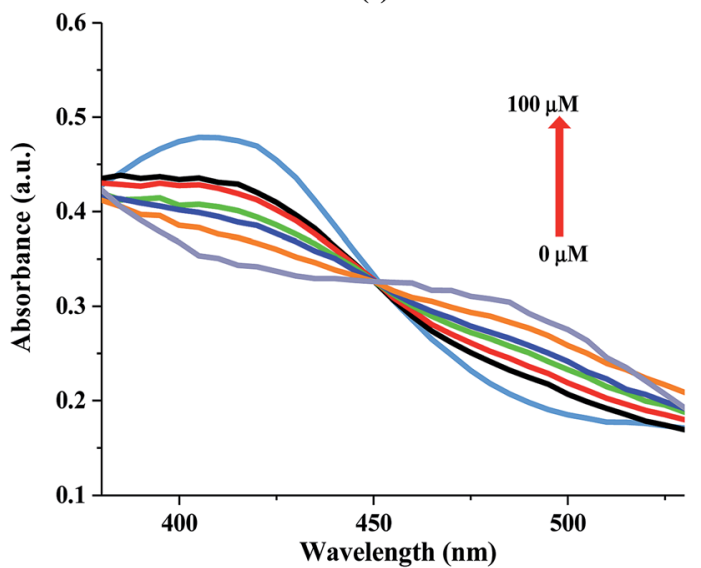

(b)

Fig. 4 (a) UV-Visible absorbance spectra of $\mathrm{NQH}$ in the presence of different metal ions and (b) UV-Visible absorbance spectra of NQH compound with varying $\mathrm{Cu}^{2+}$ concentrations. selectivity of $\mathrm{NQH}$ towards $\mathrm{Cu}^{2+}$. This facilitates the synthesized $\mathrm{NQH}$ compound as a colorimetric sensor for the detection of $\mathrm{Cu}^{2+}$. The color change arises from the $\mathrm{d}-\mathrm{d}$ electron transitions that occurs due to the absorbance of the light. ${ }^{39}$ Furthermore, the shift in the absorbance peak for $\mathrm{NQH}+\mathrm{Cu}^{2+}$ is due to metalto-ligand charge-transfer (MLCT) complexes arising from the transfer of electrons from molecular orbitals in metal to molecular orbitals in ligand. ${ }^{40,41}$

In order to determine the sensitivity of $\mathrm{NQH}$ toward $\mathrm{Cu}^{2+}$, a metal titration experiment was conducted using various $\mathrm{Cu}^{2+}$ concentrations ranging from $0 \mu \mathrm{M}$ to $100 \mu \mathrm{M}$. Fig. 4(b) shows that the absorbance peak at $485 \mathrm{~nm}$ increased linearly with the increase in the concentration of $\mathrm{Cu}^{2+}$. An increase in the $485 \mathrm{~nm}$ absorbance peak from $\sim 0.2$ to $\sim 0.3$ was observed when the concentrations of $\mathrm{Cu}^{2+}$ were increased from $0 \mu \mathrm{M}$ (blank) to 100 $\mu \mathrm{M}$. This resulted in a sensitivity of $0.0007 / \mu \mathrm{M}$ and a correlation coefficient of 0.98 for the colorimetric sensor (Fig. 5). The limit of detection (LOD) and limit of quantification (LOQ) were mathematically calculated using eqn (1) and eqn (2), respectively. ${ }^{42}$

$$
\mathrm{LOD}=3.3 \times \frac{s}{m}
$$




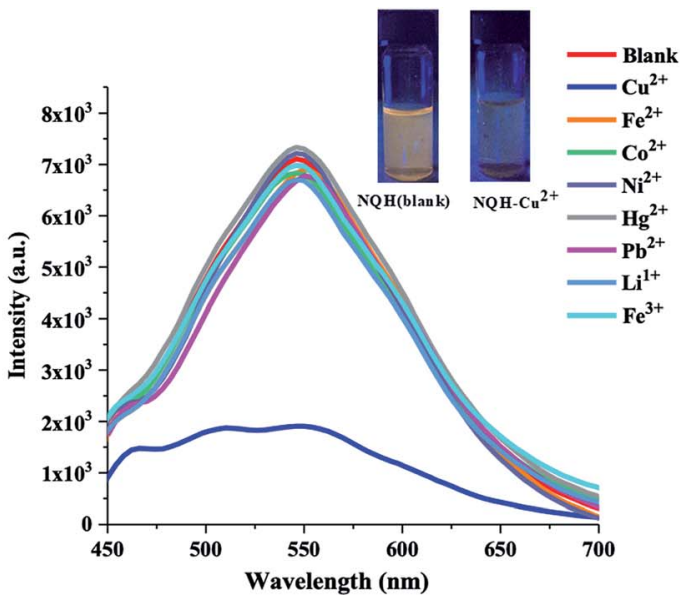

(a)

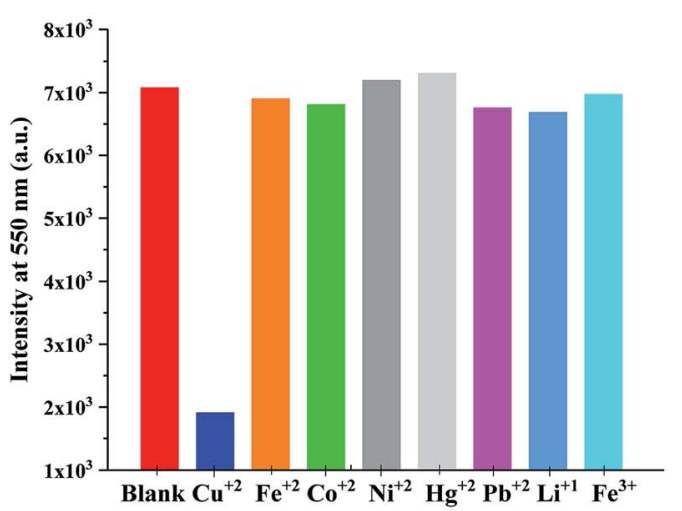

(b)

Fig. 6 (a) and (b) Fluorescence emission spectra of $\mathrm{NQH}$ in the presence of different metal ions.

$$
\mathrm{LOQ}=10 \times \frac{s}{m}
$$

where $s$ is the standard deviation ( 5 samples) of the blank, and $m$ is the slope of the regression line $y$. The LOD and LOQ for $\mathrm{Cu}^{2+}$ were found to be $3.32 \mu \mathrm{M}$ and $10.06 \mu \mathrm{M}$, respectively, which was lower than the toxicity levels of copper in drinking water $(20-30 \mu \mathrm{M})$ according to the environmental protection agency (EPA) as well as World Health Organization (WHO). ${ }^{\mathbf{4 3 , 4 4}}$

\subsection{Fluorescence study of NQH compound}

The fluorescence response of NQH compound towards various heavy metal ions was investigated at an excitation wavelength of $435 \mathrm{~nm}$ as shown in Fig. 6(a) and (b). The NQH compound exhibited a strong emission peak with maximum intensity of $\sim 7$ $\times 10^{3}$ (a.u.) at $550 \mathrm{~nm}$. The similar strong emission peaks at $\sim 550 \mathrm{~nm}$ were observed for NQH mixed with other heavy metals such as $\mathrm{Co}^{2+}, \mathrm{Ni}^{2+}, \mathrm{Fe}^{2+}, \mathrm{Fe}^{3+}, \mathrm{Li}^{1+}, \mathrm{Pb}^{2+}$, and $\mathrm{Hg}^{2+}$. However, upon adding $\mathrm{NQH}$ compound with $\mathrm{Cu}^{2+}$, the emission peak was significantly quenched by $\sim 74.5 \%$ when compared to the emission peak intensity of $\mathrm{NQH}$ compound, thus showing very high selectivity towards $\mathrm{Cu}^{2+}$ ions over other metals (Fig. 6(a) and (b)).

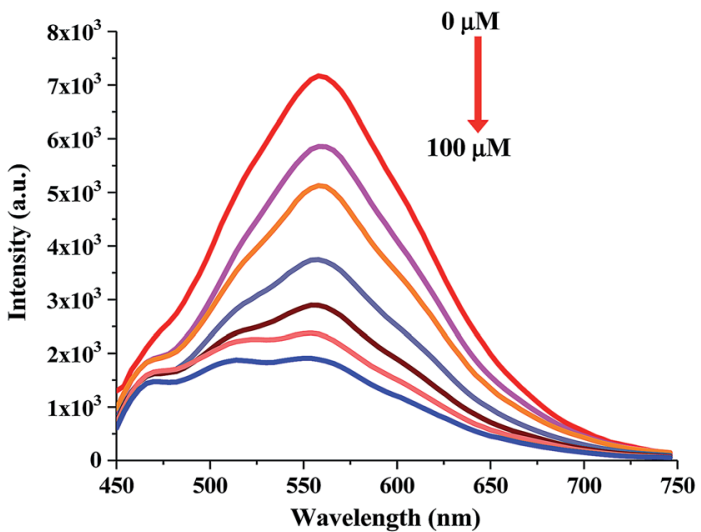

(a)

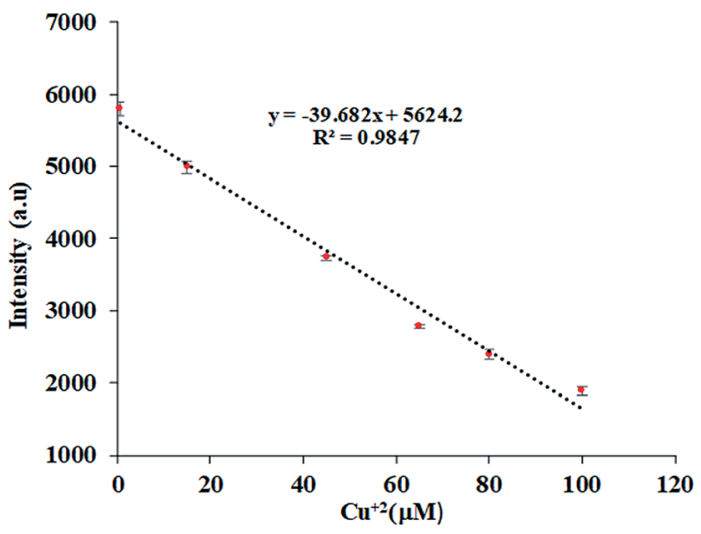

(b)

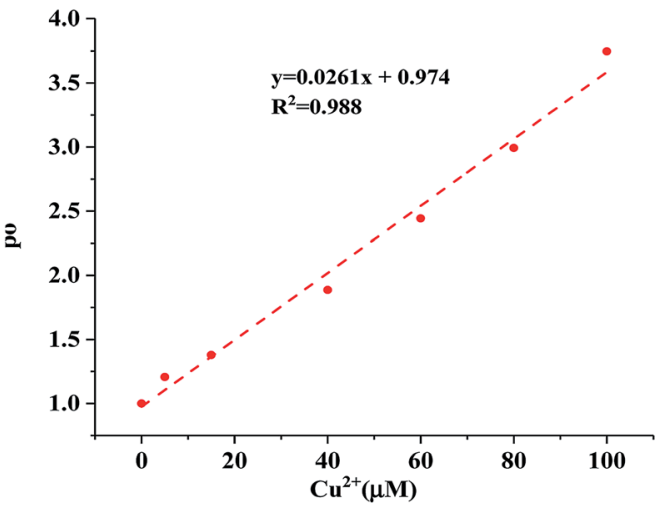

(c)

Fig. 7 (a) Fluorescence emission spectra of NQH compound towards varying $\mathrm{Cu}^{2+}$ ionic concentrations and (b) the linear plot for calculating $L O D$ and $L O Q$ and (c) relative quantum yield.

The fluorescence quenching arises from the addition of a quenching agent $\mathrm{Cu}^{2+}$ to the fluorophore $\mathrm{NQH}$, which can be interpreted in terms of chelation-induced fluorescence quenching. The fluorophore NQH itself is fluorescent when its receptor sites (nitrogen groups) are free. In the presence of $\mathrm{Cu}^{2+}$ metal ions, the fluorescence intensity of the NQH is lowered due to chelation of the $\mathrm{Cu}^{2+}$ ions to the receptor unit of the sensor. $\mathrm{NQH}$ compound with $\mathrm{Cu}^{2+}$ forms a ground-state complex, which can reduce the electron density of the complex causing the intramolecular charge-transfer effect which in turn 
quenches the fluorescence intensity. ${ }^{31,45-47}$ In addition, $\mathrm{Cu}^{2+}$ is a paramagnetic cation consisting of an unfilled $d$ shell $\left(d^{9}\right)$ and has the ability to quench the emission of nearby or surrounding fluorophores strongly through electron transfer processes. ${ }^{48}$ When $\mathrm{Cu}^{2+}$ binds to $\mathrm{NQH}$, the paramagnetic nature of $\mathrm{Cu}^{2+}$ with the unfilled $\mathrm{d}^{9}$ shell could facilitate the energy or electron transfer through a non-radiative deactivation channel, thereby quenching the fluorescence of NQH. ${ }^{49}$

The sensitivity of the NQH towards the increasing concentrations of $\mathrm{Cu}^{2+}$ from $0 \mu \mathrm{M}$ to $100 \mu \mathrm{M}$ was shown in Fig. 7(a). A decrease in the fluorescence intensity from $7.07 \times 10^{3}$ to $1.8 \times$ $10^{3}$ was observed as the concentration of the $\mathrm{Cu}^{2+}$ ions were increased from $0 \mu \mathrm{M}$ to $100 \mu \mathrm{M}$ at $\sim 550 \mathrm{~nm}$. This resulted in a sensitivity of $39.7 / \mu \mathrm{M}$ and a correlation coefficient of 0.98 for the fluorescence chemo sensor (Fig. 7(b)). A LOD and LOQ of 2.2 $\mu \mathrm{M}$ and $6.9 \mu \mathrm{M}$ was mathematically calculated using eqn (1) and eqn (2), respectively. In addition, the dynamic quenching process (Fig. 7(c)) was described using the Stern-Volmer relationship in which the quantum yield and the fluorescence intensity are related by eqn (3). ${ }^{50-52}$

$$
\frac{\Phi_{0}}{\Phi}=\frac{I_{0}}{I}=1+K_{\mathrm{sv}}[\mathrm{Q}]
$$

where $\phi_{0}$ and $\phi$ are the fluorescence quantum yields in the absence and presence of quencher ( $\mathrm{Cu}^{2+}$ ions), respectively; $I_{0}$ and $I$ are the fluorescence intensities of $\mathrm{NQH}$ in the absence and presence of quencher, respectively; $Q$ is the concentration of the $\mathrm{Cu}^{2+}$ and $K_{\mathrm{SV}}$ is the quenching rate constant. It was observed from Fig. $7(\mathrm{c})$ that the relative quantum yield $\left(\frac{\Phi_{0}}{\Phi}\right)$ or relative fluorescence intensity $\left(\frac{I_{0}}{I}\right)$ increased as the concentration of the $\mathrm{Cu}^{2+}$ ions were increased resulting in a quenching rate constant of 0.026 and a correlation coefficient of 0.988 . From eqn (3), it can be concluded that the quantum yield $(\phi)$ is inversely proportional to the concentration of $\mathrm{Cu}^{2+}$ ions.

\subsection{Binding stoichiometry}

In order to determine the coordination ratio or binding stoichiometry between the $\mathrm{NQH}$ compound and $\mathrm{Cu}^{2+}$, Job's plot experiment was performed (Fig. 8). ${ }^{53,54}$ In the Job's plot experiment, the prepared stock solution of $\mathrm{NQH}$ was $1 \mathrm{M}$ which was

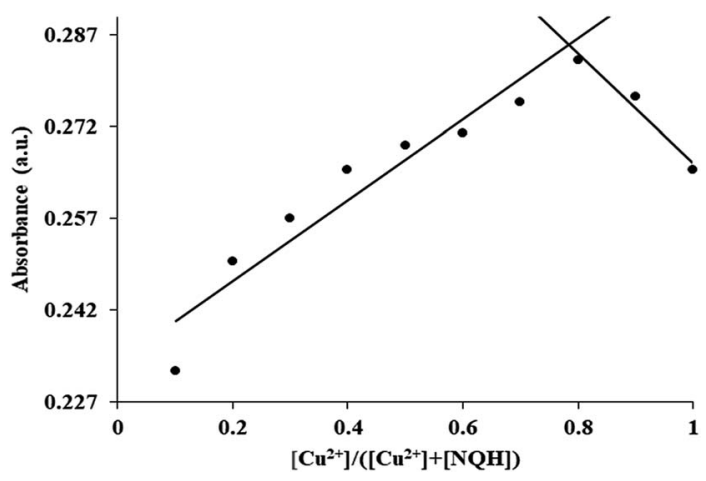

Fig. 8 Job's plot for determining the stoichiometry of $\mathrm{NQH}$ and $\mathrm{Cu}^{2+}$. then diluted to different concentrations from $0.1 \mathrm{mM}$ to $0 \mathrm{mM}$ by adding ethanol. Then $\mathrm{Cu}^{2+}$ ions from $0 \mu \mathrm{M}$ to $100 \mu \mathrm{M}$ were added to the diluted solutions of $\mathrm{NQH}$ in such a way that the total molarity of $[\mathrm{NQH}]+\left[\mathrm{Cu}^{2+}\right]$ was fixed at $0.1 \mathrm{mM}$ resulting in mole fractions of $\left[\mathrm{Cu}^{2+}\right] /\left(\left[\mathrm{Cu}^{2+}\right]+[\mathrm{NQH}]\right)$ between $0.1-1.0$. The absorbance of the $[\mathrm{NQH}]+\left[\mathrm{Cu}^{2+}\right]$ complex with different mole fractions was recorded at $485 \mathrm{~nm}$. A maximum absorbance was observed at a mole fraction of 0.75 indicating the $1: 2$ stoichiometry for $\mathrm{NQH}$ and $\mathrm{Cu}^{2+}$ complexation. The $1: 2$ stoichiometry complexation between $\mathrm{NQH}$ and $\mathrm{Cu}^{2+}$ was further confirmed by

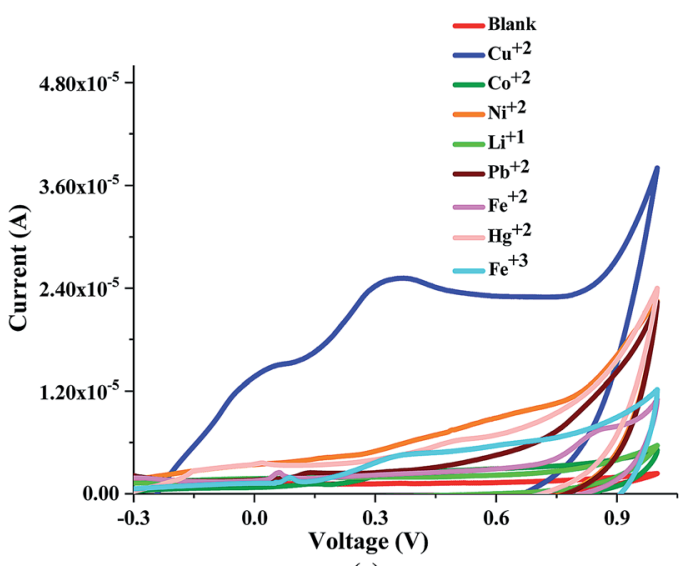

(a)

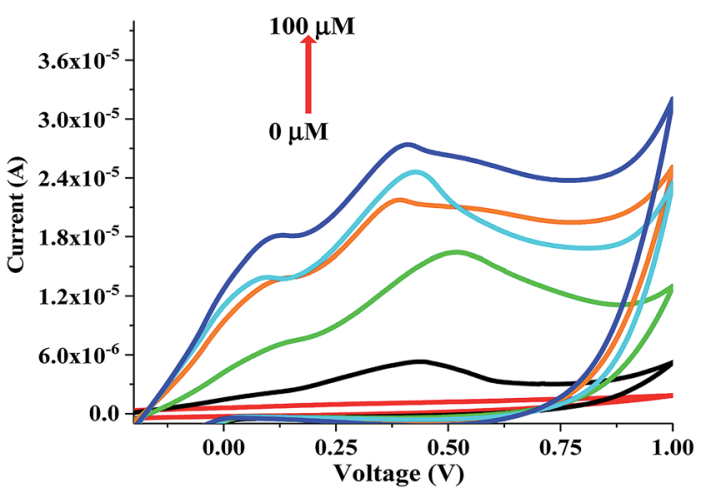

(b)

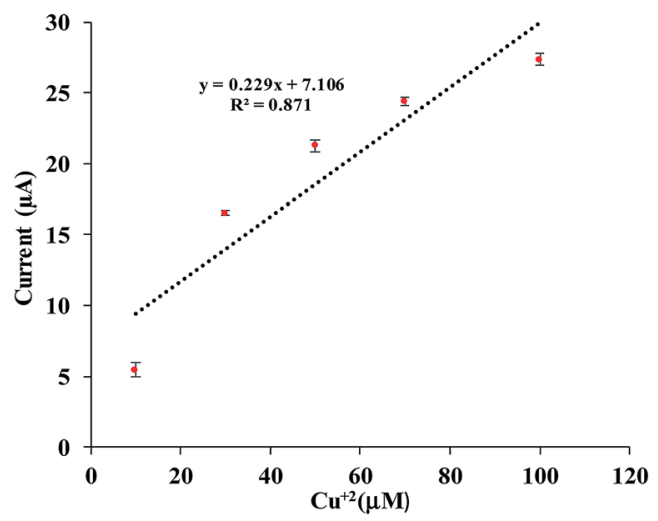

(c)

Fig. 9 (a) Cyclic voltammogram of NQH in presence of different metal ions, (b) cyclic voltammetry response of $\mathrm{NQH}$ towards varying $\mathrm{Cu}^{2+}$ concentrations and (c) linear plot for determination of LOD and LOQ. 
Table 1 Comparison summary of the performances of some reported $\mathrm{Cu}^{2+}$ sensors

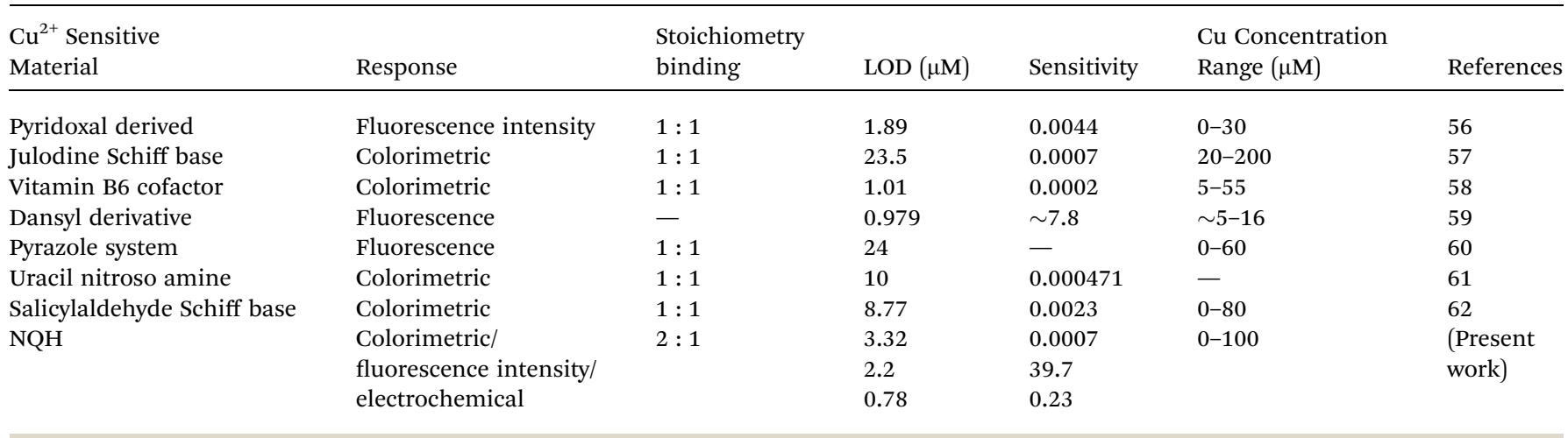

performing MALDI-TOF mass spectroscopy. The mass spectroscopy was conducted for $\mathrm{NQH}\left(\mathrm{C}_{48} \mathrm{H}_{18} \mathrm{~N}_{6} \mathrm{O}_{6}\right)$ and $\mathrm{Cu}^{2+}$ mixture with a binding ratio of $1: 2$ moles. As shown in Fig.S1(a), $\dagger$ a characteristic peak was observed at $775.0594 \mathrm{~m} / \mathrm{z}$ which corresponds to the free $[\mathrm{NQH}+\mathrm{H}]^{+}$. When $\mathrm{Cu}^{2+}$ was added to the $\mathrm{NQH}$ solution, a new characteristic peak was obtained at $1251.7280 \mathrm{~m} / z$ corresponding to $\left[\mathrm{NQH}-\mathrm{Cu}_{2}\left(\mathrm{CH}_{3} \mathrm{COO}\right)_{5} 3 \mathrm{H}_{2} \mathrm{O}+\right.$ $\mathrm{H}]^{+}$as shown in Fig. S2(b). $\dagger$ This result confirms the existence of one molecule $\mathrm{NQH}$ binding with two $\mathrm{Cu}^{2+}$ ions.

\subsection{Electrochemical study}

The CV measurements were recorded for the printed sensor towards different heavy metals including $\mathrm{Cu}^{2+}, \mathrm{Ni}^{2+}, \mathrm{Co}^{2+}, \mathrm{Fe}^{2+}$, $\mathrm{Fe}^{3+}, \mathrm{Li}^{1+}, \mathrm{Ni}^{2+}, \mathrm{Hg}^{2+}$ and $\mathrm{Pb}^{2+}$, to test the selectivity of $\mathrm{NQH}$ compound towards $\mathrm{Cu}^{2+}$ ions. The $\mathrm{CV}$ responses towards various heavy metals of $100 \mu \mathrm{M}$ were recorded from $-0.3 \mathrm{~V}$ to $1 \mathrm{~V}$ at a scan rate of $50 \mathrm{mV} \mathrm{s}^{-1}$. A peak at $\sim 0.4 \mathrm{~V}$ was obtained for the $\mathrm{Cu}$ ions and no affinity/response towards other metals were detected as shown in Fig. 9(a). Also, the anodic zone showed a clear oxidation peak at $0.4 \mathrm{~V}$ corresponding to $\mathrm{Cu}(\mathrm{I}) / \mathrm{Cu}(\mathrm{II})$. This behavior clearly demonstrated that $\mathrm{Cu}$ is present in the complex as $\mathrm{Cu}^{2+}$ ion which is comparable with previous literature. ${ }^{55}$ These results clearly indicate that the NQH drop casted sensor possess excellent selectivity towards $\mathrm{Cu}^{2+}$. The selectivity of $\mathrm{NQH}$ compound towards only $\mathrm{Cu}^{2+}$ ions is due to the chelation of the $\mathrm{Cu}^{2+}$ ions by the free nitrogen groups resulting in a complex formation between nitrogen and $\mathrm{Cu}^{2+}$ ions.

Fig. 9(b) shows the CV response of the NQH drop-casted electrochemical sensor towards various ionic concentrations of $\mathrm{Cu}^{2+}$ ion solutions. An increase in the prominent peak current from $1.1 \mu \mathrm{A}$ to $27.4 \mu \mathrm{A}$ was observed at $\sim 0.4 \mathrm{~V}$ when the $\mathrm{Cu}^{2+}$ ion concentrations were increased from blank (DI water) to $100 \mu \mathrm{M}$, respectively. A sensitivity of $0.23 \mu \mathrm{A} \mu \mathrm{M}^{-1}$ and a correlation coefficient of 0.87 was obtained for the electrochemical sensor (Fig. 9(c).) In addition, a LOD of $0.78 \mu \mathrm{M}$ and LOQ of 2.37 $\mu \mathrm{M}$ was calculated which is below the $\mathrm{Cu}^{2+}$ toxicity levels set by EPA and WHO.

In addition, the EIS response were recorded at $1 \mathrm{~V}$ and operating frequency ranging from $20 \mathrm{~Hz}$ to $20 \mathrm{kHz}$ to verify the selectivity of the NQH drop-casted sensor (Fig. S2 $\uparrow$ ). A reference impedance signal of $713 \mathrm{k} \Omega$ was measured initially at $20 \mathrm{~Hz}$ by drop casting DI water on the sensor. Then, a very high impedance of $171 \mathrm{k} \Omega$ was observed at $20 \mathrm{~Hz}$ for $\mathrm{Cu}^{2+}$ when compared to impedance of $31 \mathrm{k} \Omega, 57 \mathrm{k} \Omega, 39 \mathrm{k} \Omega, 53 \mathrm{k} \Omega, 16 \mathrm{k} \Omega$ and $66 \mathrm{k} \Omega$ for various metal ions $\mathrm{Ni}^{2+}, \mathrm{Co}^{2+}, \mathrm{Li}^{1+}, \mathrm{Fe}^{3+}, \mathrm{Hg}^{2+}$ and $\mathrm{Pb}^{2+}$, respectively. This results clearly indicate that the sensor was able to distinguish $\mathrm{Cu}^{2+}$ among various other metal ions. A comparison summary of the current work with some reported $\mathrm{Cu}^{2+}$ sensors is shown in Table 1. It can be noticed that the developed $\mathrm{Cu}^{2+}$ sensor of this work has an appreciable LOD and sensitivity when compared to some of the reported $\mathrm{Cu}^{2+}$ sensors.

\section{Conclusion}

A novel HAT derivative based NQH compound was synthesized for selective detection of $\mathrm{Cu}^{2+}$ ions in water. The capability of the NQH compound to be employed as a colorimetry, chemofluorescence and electrochemical sensor for the detection of $\mathrm{Cu}^{2+}$ was demonstrated by performing UV-Vis absorbance, fluorescence intensity, and cyclic voltammetry measurements. UV-Vis absorbance and fluorescence of $\mathrm{NQH}$ toward $\mathrm{Cu}^{2+}$ showed a good linearity with a detection limit of $3.32 \mu \mathrm{M}$ and $2.20 \mu \mathrm{M}$, respectively. Job's plot and mass spectroscopy results revealed a 1:2 stoichiometry complexation between $\mathrm{NQH}$ and $\mathrm{Cu}^{2+}$. In addition, the selectivity and sensitivity of $\mathrm{NQH}$ compound towards $\mathrm{Cu}^{2+}$ ions was further confirmed by performing cyclic voltammetry on a screen printed flexible and planar electrochemical sensor. Future work includes optimization of the performance of the sensors in terms of sensitivity and LOD as well as LOQ by varying the quantity of $\mathrm{NQH}$ compound specifically for UV-Vis absorbance as well as fluorescence measurements and by adding the salts to increase the electrolytic activity for electrochemical measurements.

\section{Conflicts of interest}

There are no conflicts to declare.

\section{References}

1 Y. Shan, M. Tysklind, F. Hao, W. Ouyang, S. Chen and C. Lin, J. Soils Sediments, 2013, 13(4), 720-729. 
2 P. B. Tchounwou, C. G. Yedjou, A. K. Patlolla and D. J. Sutton, Molecular, clinical and environmental toxicicology, Springer, 2012, pp. 133-164.

3 P. C. Nagajyoti, K. D. Lee and T. V. M. Sreekanth, Environ. Chem. Lett., 2010, 8(3), 199-216.

4 Z. Rahman and V. P. Singh, Environ. Monit. Assess., 2019, 191(7), 419.

5 R. Chander, S. Naveen, K. Arora and R. Kothari, Environmental Biotechnology: For Sustainable Future, 2018.

6 R. A. Festa and D. J. Thiele, Curr. Biol., 2011, 21(21), R877R883.

7 B. R. Stern, J. Toxicol. Environ. Health, Part A, 2010, 73(2-3), 114-127.

8 N. Barnes, R. Tsivkovskii, N. Tsivkovskaia and S. Lutsenko, J. Biol. Chem., 2005, 280(10), 9640-9645.

9 I. F. Scheiber, J. F. B. Mercer and R. Dringen, Prog. Neurobiol., 2014, 116, 33-57.

10 D. J. Waggoner, T. B. Bartnikas and J. D. Gitlin, Neurobiol. Dis., 1999, 6(4), 221-230.

11 J. Emerit, M. Edeas and F. Bricaire, Biomed. Pharmacother., 2004, 58(1), 39-46.

12 H. Zischka and C. Einer, Int. J. Biochem. Cell Biol., 2018, 102, 71-75.

13 V. Chrastny and M. Komarek, Chem. Pap., 2009, 63(5), 512519.

14 C. Karadas, O. Turhan and D. Kara, Food Chem., 2013, 141(2), 655-661.

15 L. Zhao, S. Zhong, K. Fang, Z. Qian and J. Chen, J. Hazard. Mater., 2012, 239, 206-212.

16 R. L. Nixon, S. L. Jackson, J. T. Cullen and A. R. S. Ross, Mar. Chem., 2019, 103673.

17 K. T. Makhmudov, R. A. Alieva, S. R. Gadzhieva and F. M. Chyragov, J. Anal. Chem., 2008, 63(5), 435-438.

18 M. Z. Atashbar, B. E. Bejcek and S. Singamaneni, IEEE Sens. J., 2006, 6(3), 524-528.

19 B. Ziaie, A. Baldi and M. Z. Atashbar, Springer handbook of nanotechnology, 2004, pp. 147-184.

20 Y. Fu, C. Fan, G. Liu and S. Pu, Sens. Actuators, B, 2017, 239, 295-303.

21 S. Chaiyo, W. Siangproh, A. Apilux and O. Chailapakul, Anal. Chim. Acta, 2015, 866, 75-83.

22 J. Wu, W. Pisula and K. Mullen, Chem. Rev., 2007, 107(3), 718-747.

23 J. E. Anthony, Chem. Rev., 2006, 106(12), 5028-5048.

24 J. L. Segura, R. Juarez, M. Ramos and C. Seoane, Chem. Soc. Rev., 2015, 44(19), 6850-6885.

25 L. Zhang, Y. Cao, N. S. Colella, Y. Liang, J. L. Bredas, K. N. Houk and A. L. Briseno, Acc. Chem. Res., 2015, 48(3), 500-509.

26 L. Chen, Y. Hernandez, X. Feng and K. Mullen, Angew. Chem., Int. Ed., 2012, 51(31), 7640-7654.

27 S. Kitagawa and S. Masaoka, Coord. Chem. Rev., 2003, 246(12), 73-88.

28 B. R. Kaafarani, Chem. Mater., 2010, 23(3), 378-396.

29 T. Ishi-i, K. Yaguma, R. Kuwahara, Y. Taguri and S. Mataka, Org. Lett., 2006, 8(4), 585-588.
30 X. Y. Yan, M. Di Lin, S. T. Zheng, T. G. Zhan, X. Zhang, K. Da Zhang and X. Zhao, Tetrahedron Lett., 2018, 59(7), 592-604.

31 Y. Li, L. Le Yang, K. Liu, F. Y. Zhao, H. Liu and W. J. Ruan, New J. Chem., 2015, 39(4), 2429-2432.

32 X. H. Zhang, Q. Zhao, X. M. Liu, T. L. Hu, J. Han, W. J. Ruan and X. H. Bu, Talanta, 2013, 108, 150-156.

33 X. H. Zhang, C. F. Zhao, Y. Li, X. M. Liu, A. Yu, W. J. Ruan and X. H. Bu, Talanta, 2014, 119, 632-638.

34 Y. Meng, Z. B. Li, X. Chen and J. P. Chen, Microsyst. Technol., 2015, 21(6), 1241-1248.

35 V. S. Turkani, D. Maddipatla, B. B. Narakathu, T. S. Saeed, S. O. Obare, B. Bazuin and M. Z. Atashbar, Nanoscale Adv., 2019, 1, 2311-2322.

36 A. A. Chlaihawi, B. B. Narakathu, S. Emamian, B. J. Bazuin and M. Z. Atashbar, Sens. Bio-Sens. Res., 2018, 20, 9-15.

37 B. Narakathu, M. Sajini, A. Reddy, A. Eshkeiti, A. Moorthi, I. R. Fernando, B. P. Miller, G. Ramakrishna, E. Sinn, M. Joyce, M. Rebros, E. Rebrosova, G. Mezei and M. Atashbar, Sens. Actuators, B, 2013, 176, 768-774.

38 M. M. Ali, D. Maddipatla, B. B. Narakathu, A. A. Chlaihawi, S. Emamian, F. Janabi, B. J. Bazuin and M. Z. Atashbar, Sens. Actuators, A, 2018, 274, 109-115.

39 L. Fabbrizzi, M. Licchelli and P. Pallavicini, Acc. Chem. Res., 1999, 32(10), 846-853.

40 Q. Hu, K. Ma, Y. Mei, M. He, J. Kong and X. Zhang, Talanta, 2017, 167, 253-259.

41 S. S. M. Rodrigues, D. R. Prieto, D. S. M. Ribeiro, E. Barrado, J. A. V. Prior and J. L. M. Santos, Talanta, 2015, 134, 173-182. 42 L. H. Jin and C. S. Han, Anal. Chem., 2014, 86(15), 7209-7213. 43 https://archive.epa.gov/, (n.d.).

44 https://www.fda.gov/, (n.d.).

45 L. J. Fan, J. J. Martin and W. E. Jones, J. Fluoresc., 2009, 19(3), 555-559.

46 Y. Du, M. Chen, Y. Zhang, F. Luo, C. He, M. Li and X. Chen, Talanta, 2013, 106, 261-265.

47 S. S. Tan, S. J. Kim and E. T. Kool, J. Am. Chem. Soc., 2011, 133(8), 2664-2671.

48 H. S. Jung, P. S. Kwon, J. W. Lee, J. I. I. Kim, C. S. Hong, J. W. Kim, S. Yan, J. Y. Lee, J. H. Lee, T. Joo and J. S. Kim, J. Am. Chem. Soc., 2009, 131, 2008-2012.

49 R. Kramer, Angew. Chem., Int. Ed., 1998, 37, 772-773.

50 W. S. Jeon, T. J. Park, K. H. Kim, R. Pode, J. Jang and J. H. Kwon, Org. Electron., 2010, 11, 179-183.

51 M. K. Seery, N. Fay, T. McCormac, E. Dempsey, R. J. Forster and T. E. Keyes, Phys. Chem. Chem. Phys., 2005, 7, 3426-3433.

52 E. J. Bowen, Q. Rev., Chem. Soc., 1947, 1, 1-15.

53 P. Job, Ann. Chim. Phys., 1928, 9, 113-203.

54 J. Plots, J. S. Renny, L. L. Tomasevich, E. H. Tallmadge and D. B. Collum, Angew. Chem., Int. Ed., 2013, 52(46), 1199812013.

55 R. Fekri, M. Salehi, A. Asadi and M. Kubicki, Polyhedron, 2017, 128, 175-187.

56 S. K. Sahoo, D. Sharma, A. Moirangthem, A. Kuba, R. Thomas, R. Kumar, A. Kuwar, H. J. Choi and A. Basu, J. Lumin., 2016, 172, 297-303.

57 Y. W. Choi, J. J. Lee, G. R. You, S. Y. Lee and C. Kim, RSC Adv., 2015, 5, 86463-86472. 
58 D. Sharma, A. Kuba, R. Thomas, R. Kumar, H. J. Choi and S. K. Sahoo, Spectrochim. Acta, Part A, 2016, 153, 393-396.

59 A. Thangaraj, V. Bhardwaj and S. K. Sahoo, Photochem. Photobiol. Sci., 2019, 18, 1533-1539.

60 T. Mistri, R. Alam, M. Dolai, S. K. Mandal, A. R. KhudaBukhsh and M. Ali, Org. Biomol. Chem., 2013, 11, 1563-1569.
61 S. R. Patil, J. P. Nandre, P. A. Patil, S. K. Sahoo, M. Devi, C. P. Pradeep, Y. Fabiao, L. Chen, C. Redshaw and U. D. Patil, RSC Adv., 2015, 5, 21464-21470.

62 K. Y. Ryu, J. J. Lee, J. A. Kim, D. Y. Park and C. Kim, RSC Adv., 2016, 6, 16586-16597. 